\title{
The 110th Anniversary of Academician Alexander Evseevich Braunstein
}

\author{
T. V. Demidkina \\ Engelhardt Institute of Molecular Biology, Russian Academy of Sciences \\ E-mail: tvd@eimb.ru
}

A lexander Evseevich Braunstein, the well-known enzymologist, was born on May 26, 1902, into a medical family. His father was an ophthalmologist, a professor of Kharkov Medical Institute and the President of the Kharkov Medical Society.

In 1913, Alexander Braunstein enrolled in a gymnasium, directly entering the third grade, since by that time he had already received a thorough and all-round home education. Alexander Braunstein was fluent in German, English, and French, which, by his own admission, assisted him greatly in his scientific work and was an additional source of income. Alexander Braunstein began to display an interest in the sciences at an early age. In his childhood, he was keen on chemistry and had a small chemistry laboratory at home. Having graduated from the gymnasium in 1920, he entered Kharkov Medical Institute, being as it were at the time the only place in the Ukraine where one could receive higher education in the field of natural sciences.

A.E. Braunstein began his scientific research in 1925 as a postgraduate student of the very first postgraduate course in the USSR. His scientific adviser at the Institute of Biochemistry of the People's Commissariat for Health, in Moscow, was V.A. Engelhardt. In 1928, A.E. Braunstein defended his candidate dissertation devoted to the study of the interrelation be- tween glycolysis and the phosphate metabolism in red blood cells. During the period from 1928 to 1936, Alexander Evseevich Braunstein immersed himself in the investigation of the processes of oxidative and respiratory phosphorylation and detoxification of aromatic compounds. In the aforementioned, as well as subsequent studies, Braunstein's excellent knowledge of chemistry and three foreign languages helped him to perform the research at a very high and contemporary biochemical level. In the XX century, biochemistry was making very rapid progress and shifting from the description of metabolic processes to the establishment of their molecular mechanisms.

In 1936, A.E. Braunstein took the helm at the Laboratory of Intermediate Nitrogen Metabolism at the Gorky All-Union Institute of Experimental Medicine. In 1937, working in cooperation with M.G. Kritsman, he discovered a new enzymatic reaction representing the transfer of an amino group from $\alpha$-amino acids to keto acids; this reaction was named transamination [1]. This discovery, one of the greatest in biochemistry in the $\mathrm{XX}$ century, was of fundamental importance in understanding the pathways of assimilation and dissimilation of nitrogen. From then on, A.E. Braunstein's research was almost entirely focused on the study of the enzymatic transformations of amino acids and the establishment of the role of transamination reactions in metabolism. This work was interrupted by the Second World War and resumed in 1945 at the Institute of Biological and Medical Chemistry, USSR Academy of Medical Sciences.

Among the investigations performed by A.E. Braunstein in that period, the following should be noted: the experimental confirmation of his hypothesis put forth in 1939; according to the hypothesis, the concerted action of transaminase and glutamate dehydrogenase plays a key role in the metabolism of nitrogen and its conjugation with energy processes in the cell [2]. Following the discovery in 1944-1945 (in the USA and Great Britain) of the participation of pyridoxal-5'phosphate (vitamin B6) in the enzymatic reactions of transamination and decarboxylation, intensive studies of the role of pyridoxal-5'phosphate in nitrogen metabolism began at the laboratory headed by A.E. Braunstein. Previously unknown pyridoxal-5'phosphatedependent reactions of the transformation of tryptophan, serine, cysteine, and their analogs were discovered. In 1949, A.E. Braunstein published a brilliant paper concerning the pathways of the transformation of $L$-tryptophan in animals [3]. Firstly, the metabolic reactions suggested in the work were later empirically confirmed via experimental studies performed soon af- 


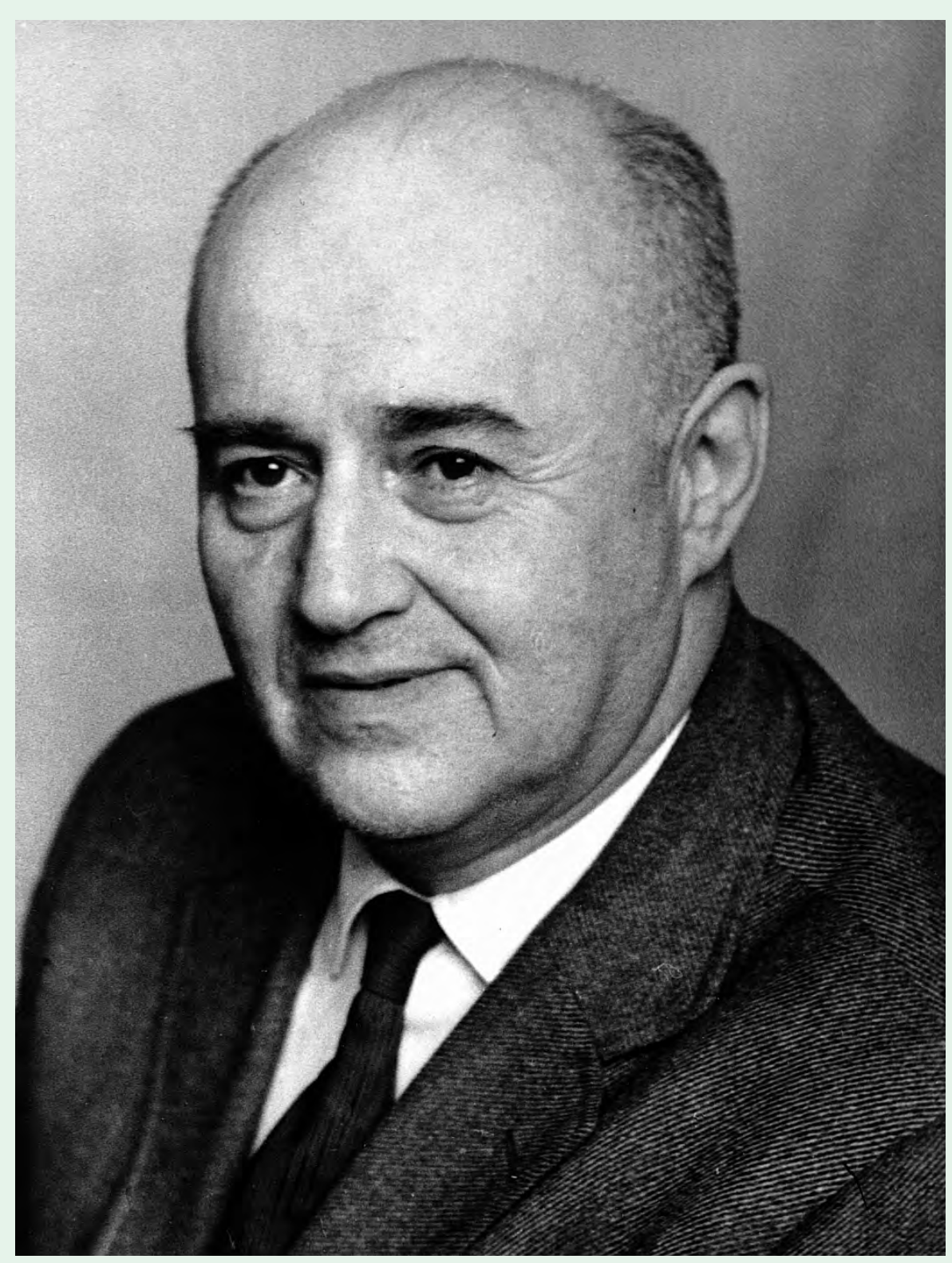

Alexander Evseevich Braunstein

terwards. Secondly, the hypothesis that the participation of pyridoxal5'-phosphate in the by-then-known enzymatic transformations of amino acids could be explained by the electron properties of a coenzyme molecule was suggested; the hypothesis was a prerequisite for the general theory of pyridoxal catalysis. Thirdly, the mechanism of the breakdown of $L$-kynurenine, dif- ferent from those given by nonRussian researchers, was suggested. In 1998, evidence confirming the validity of Braunstein's mechanism was obtained [4]. It should be noted that all the suggestions and conclusions E.A. Braunstein made owed a debt to his solid knowledge of organic chemistry.

The general theory of pyridoxal5'-phosphate-dependent catalysis was formulated by A.E. Braunstein and M.M. Shemyakin in 1952-1953. This theory considered the electron peculiarities of pyridoxal-5'-phosphate, which is responsible for its ability to catalyze various chemical reactions, and postulated that the protein matrix of enzymes is one of the factors behind their reaction specificity [5]. A year later, American researchers (Snell E.E. et al.) proposed an analogous theory [6]. These works not only formed the basis for the explanation of the mechanism of the action of pyridoxal-5'-phosphate enzymes, but also spurred studies of the mechanisms in other coenzyme-dependent reactions.

In 1960, A.E. Braunstein was invited by V.A. Engelhardt to work for the Institute of Radiation and Chemical Biology, USSR Academy of Sciences (later renamed into the Institute of Molecular Biology, the USSR Academy of Sciences), at which he organized the Laboratory of Chemical Principles of Biocatalysis. In his autobiography (1981), A.E. Braunstein wrote: "Since then, our group has focused primarily on the study of the molecular structure and detailed catalytic mechanism of the main types of pyridoxal-5'phosphate-dependent enzymes by applying novel chemical and physical approaches". In the recently established institute, V.A. Engelhardt brought together scientists specializing in various scientific fields and with various scientific interests, thereby enabling the performance of complex studies, which greatly promoted the development of molecular enzymology in Russia. At present, the followers of A.E. Braunstein, a founder of molecular enzymology in Russia, work in many different fields of physicochemical biology.

Among the most important works of A.E. Braunstein and his colleagues, the following should be noted: the dynamic molecular 
model of enzymatic transamination developed in 1986 [7]; the determination of the amino acid sequence of aspartate aminotransferase from the cytosol of the pig's heart [8] (in collaboration with Yu.A. Ovchinnikov and researchers from the Institute of Bioorganic Chemistry); and the determination of the spatial structure of aspartate aminotransferase from the cytosol of the hen's heart (1977) (in collaboration with B.K.Vainstein and researchers from Shubnikov Institute of Crystallography) [9]. A.E. Braunstein summed up the main results of his versatile research in a book [10] published after his death on July 1, 1986.

In 1936, A.E. Braunstein married Sofia Vilgelmovna Kreiden. His wife played an important role in his scientific career, always supporting him; A.E. Braunstein wrote: "her irresistible charm and devoted care maintain a unique at- mosphere of harmony and happiness at our home". Anyone who has had an occasion to work alongside, or indeed meet Alexander Evseevich, remembers not only his unique scientific knowledge, but also his unfailing kindness, friendliness, and their hospitality with Sofia Vilgelmovna.

A.E. Braunstein paid a great deal of attention to scientific and organizational work. He sat on the editorial boards of many Russian and non-Russian journals, academic boards, and was a member of various biochemical societies. His encyclopedic knowledge assisted in the development of the principles of a classification system for enzymes and a biochemical nomenclature.

A.E. Braunstein received wide international recognition for his work, commanding significant scientific authority in Russia and abroad. Many foreign scientists visited and worked at the Laboratory of Chemical Principles of Biocatalysis.

It is hard to overstate the influence of Braunstein's ideas on today's physicochemical biology and molecular enzymology. A.E. Braunstein was elected a full-fledged member of the Academy of Medical Sciences (1945) and the USSR Academy of Sciences (1964). He was awarded honorary doctorates from the Universities of Brussels, Greifswald, and Paris VII, and he held honorary membership in scientific societies and academies of sciences in a number of countries, including the Nation Academy of Sciences of the USA.

A.E. Braunstein won the State Prize (1941) and the Lenin Prize (1980) in the field of science and technology, and he was awarded the title of Hero of Socialist Labor (1972), and two Orders of the Red Banner of Labor.

\section{REFERENCES}

1. Braunstein A.E., Kritsman M.G. // Bulletin of Experimental Biology and Medicine. 1937. V. 3. P. 246-248.

2. Braunstein A.E. // Adv. Enzymol. 1957. V. 19. P. 335-389.

3. Braunstein A.E. // Doklady AN SSSR. 1949. V. 65. P. 715-718.

4. Phillips R.S., Sundararaju B., Koushik S.V. // Biochemistry. 1998. V. 37. P. 1376-1382.

5. Braunstein A.E., Shemyakin M.M. // Biokhimia. 1953. V. 18. P. 393-411.

6. Metzler D.E., Ikawa M., Snell E.E. // J. Am. Chem. Soc. 1954. V. 76. P. 648-652.

7. Braunstein A.E., Ivanov V.I., Karpeisky M.Ya. Pyridoxal Catalysis: Enzymes and Model Systems. J. Wiley \& Sons,
Inc., 1968.

8. Ovchinnikov Yu.A., Braunstein A.E., Egorov C.A., Polyanovsky O.L., Aldanova N.A., Feigina M.Y., Lipkin V.M., Abdulaev N.G., Grishin E.V., Kiselev A.P., Modyanov N.N., Nosikov V.V. // Doklady AN SSSR. 1972. V. 207. P. 728-731.

9. Borisov V.V., Borisova S.N., Kachalova G.S., Sosfenov N.I., Voronova A.A., Vainshtein B.K. Torchinsky Yu.M., Volkova G.A., Braunstein A.E. // Doklady AN SSSR. 1977. V. 235. P. $212-215$.

10. Braunstein A.E. Protsess Processy i fermenty kletochnogo metabolizma (The Processes and Enzymes of Cellular Metabolism). M.: Nauka. 1987. 552 p. 